\title{
Granular cell tumor (Abrikossoff's tumor) of the labium majus: a case report
}

\author{
Reza Yaghoobi ${ }^{1}$, Nemat A Jazayeri ${ }^{2}$, Farzaneh Alamshahi ${ }^{*}$, Nooshin Bagherani ${ }^{4}$, Nahid Shahbazian ${ }^{5}$, Mahru Tajalli $^{6}$ and Majid Mehri $^{6}$ \\ ${ }^{1}$ Professor of Dermatology, Department of Dermatology, Jundishapour University of Medical Sciences, Ahvaz, Iran \\ ${ }^{2}$ Assistant professor of Pathology, Department of Pathology, Ahvaz Jundishapour University of Medical Sciences, Ahwaz, Iran \\ ${ }^{3}$ Resident of Dermatology, Department of Dermatology, Ahvaz Jundishapour University of Medical Sciences, Ahvaz, Iran \\ ${ }^{4}$ Dermatologist, Taha Physicians' Building, Khoramshahr, Khuzestan Province, Iran \\ ${ }^{5}$ Assistant professor of Gynecology and Obstetrics, Department of Gynecology and Obstetrics, Ahvaz Jundishapour University of Medical Sciences, Ahwaz, Iran \\ ${ }^{6}$ Dermatologist, Iran
}

\begin{abstract}
Granular Cell Tumor (GCT) is an uncommon, benign tumor of neural origin resembling Schwann cells. It is more common in females and blacks. Head and neck regions are the most sites involved by the tumor, but it can occur in any part of the body. Vulva, ovary and cervix in females and scrotum in males can present GCT. The importance of this tumor is potential malignant transformation in rarity. Total excision is the choice treatment for GCT because of probability of recurrences.

In this article, we described a case of granular cell tumor of the labium majus in a 21-year old lady, from southwest of Iran. Subsequent investigations confirmed positive results for S100 protein and neuron specific enolase, but Periodic Acid Schiff (PAS) staining was negative.
\end{abstract}

Our findings confirmed neural origin for GCT.

\section{Introduction}

Granular Cell Tumors (GCTs), neoplastic skin and soft tissue lesions [1], were initially described by Weber in 1854 [1,2]. They were also described by Abrikissof in 1926 [3]. They are uncommon, benign tumors of neural origin resembling Schwann cells [4], which occur in less than $0.1 \%$ of surgical specimens [1]. The Schwann cell origin of GCT was reported in the 1960's [2]. Till 1999, approximately 400 cases of GCTs had been reported in the literature, that vulvar involvement had accounted for $7-16 \%$ of this [4].

There is a female predominance [5,6]. The average age of presentation is 40-50 years, but the tumors may arise in children [5]. The most common sites involved are the head and neck regions, although GCTs have been found in all areas of the body. GCTs of the female genital region have been documented to occur on the vulva, the ovary, and the cervix [1].

GCTs generally have the following gross characteristics: small size $(<5 \mathrm{~cm})$, firm texture, whitish color, lack of encapsulation, and submucosal or subcutaneous location [1].

Herein, we described a case of granular cell tumor of the labium majus in a 21-year old lady.

\section{Case presentation}

The patient was a 21-year-old lady, single, from southwest of Iran, referred to us with complaint of presence of a mass on the vulva. She described that it developed 2 years ago as a small-sized lesion, evolved to a large mass during 1 month after the initial appearance. After this significant growth, it has not had any noticeable change in the size. She also complained of a little pain and pruritus in its surface. The patient did not have any history of trauma and infection in involved region prior to appearance of the lesion. She did not describe a history of such lesion in her family.

On physical examination, there was a firm, grayish yellow-colored tumoral lesion, $3 \times 2 \times 2 \mathrm{~cm}$ in diameter, in left labium majus with welldefined boarder (Figure 1). It was not tender in palpation. Other clinical findings were normal, and we did not find any similar lesion in other region.

A deep sample of this, $3 \times 4 \times 6 \mathrm{~mm}$ in diameter, was biopsied with differential diagnoses of adnexal tumors, fibroma and calcified epidermal cyst.

Her routine laboratory tests were in normal limit. The pathological findings revealed involvement of dermis with a neoplastic tissue composed of cords and nests of tumoral cells with abundant granular eosinophilic cytoplasm and small round central nucleus, suggestive for the diagnosis of granular cell tumor (Figures 2 and 3). Subsequent investigations confirmed positive results for $\mathrm{S} 100$ protein and neuron

Correspondence to: Dr. Farzaneh Alamshahi, Emam Khomeini Hospital, 61335, Ahvaz, Iran P.O.Box: 61335 - 4156, Fax: +98- 611-3381110; E-mail: dr.alamshahi@yahoo.com

Key words: granular cell tumor, Abrikossoff, vulva, labium majus

Received: August 26, 2015; Accepted: October 05, 2015; Published: October 09,2015 


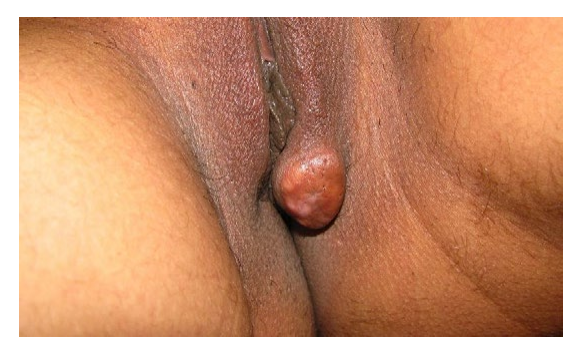

Figure 1. Granular cell tumor, manifested as a single tumoral mass in labium majus, in a 21-year-old woman.

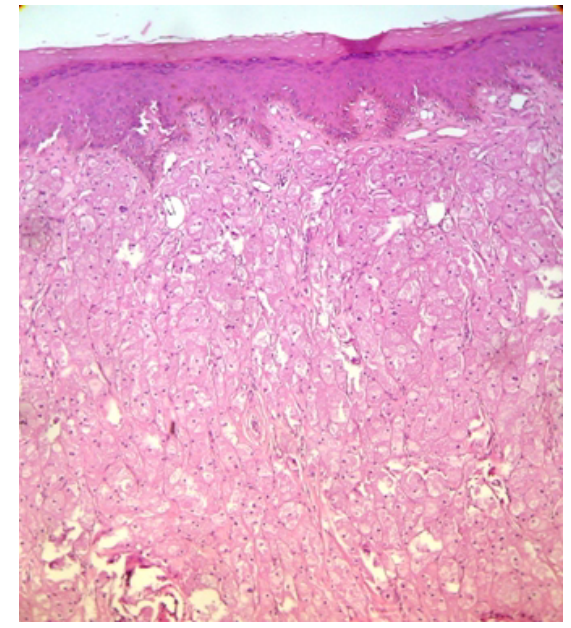

Figure 2. Pathological view of granular cell tumor showing cords and nest of tumoral cells with abundant granular eosinophilic cytoplasm and round central nucleus (Hematoxylin and Eosin, $\times 10$ )/

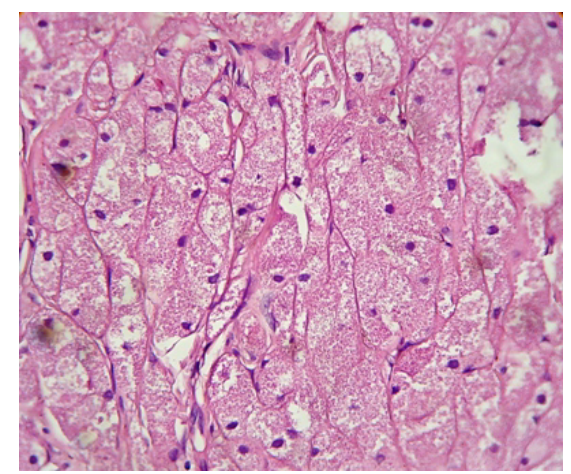

Figure 3. Pathological view of the same section as shown in Figure 2 (Hematoxylin and $\operatorname{Eosin}, \times 40)$.

specific enolase, but Periodic Acid Schiff (PAS) staining was negative (Figures 4 and 5).

After confirmation of the diagnosis, she referred to a gynecologist. Under general anesthesia, the whole mass was completely excised, $3 \times 1.5 \times 2 \mathrm{~cm}$ in diameter. The final pathological investigation also confirmed granular cell tumor, without tumoral necrosis and mitotic activity regarding to malignant transformation, excised with free margins. After 3 month- follow-up, no recurrence was seen.

\section{Discussion}

GCT is an uncommon, benign tumor of disputed histogenesis [5]. The use of 19 different descriptive synonyms attests to the uncertainty regarding its nature [3]; some of which include granular cell myoblastoma, granular cell schwannoma, and granular cell tumor $[1,7]$. Various cell types have been implicated in the histogenesis of GCT including skeletal and smooth muscle cells, fibroblasts, and histiocytes [1,7]. Most of the histochemical and ultrastructural evidence supports the schwann cell derivation of these tumors $[1,4,5]$, therefore granular cell schwannoma may be the most appropriate term for these tumors [1].

Women are more affected than men [5,6], and blacks more than whites [6]. They are most commonly seen in African Americans [2]. Age incidence has varied, from 6 to 70 years, with a mean age of 38.1 years [4]. Familial occurrence has rarely been reported. It is conceivable that familial predisposition to benign lesions is more prevalent in a setting of multiple tumors [3].

Although the majority of these tumors are benign [8], approximately 1-2 percent of GCTs are malignant [2,9], which is aggressive, with local recurrence rates up to $70 \%$ and 3 -year survival rates of less than $50 \%$ [8].

Clinical manifestations of GCTs are varied. Many present as cutaneous nodules, that overlying skin of which may be normal, hyperpigmented, or with a covering hair [2]. Most lesions are asymptomatic, solitary nodules, less than $2 \mathrm{~cm}$ in diameter [5]. They can also be either pruritic or painful [2]. Our patient also complained of pruritus and a little pain. They are multiple in about $10 \%$ of cases [5]. In one study, $29 \%$ of cases presented multiple lesions [3]. Evaluation of patients over a long period in the latter, may account for this difference [3]. Multiple lesions are more frequent in blacks [3].

GCTs may develop in many anatomical sites [5]; one half of the tumors is found in the head and neck region, with the tongue being the most common site. One third will develop on the tongue, one third on the skin and one third in internal organs [2]. Hence, the occurrence of the tumor outside the skin, head and neck is uncommon [3]. In the female genital tract, this tumor may be found in the vulva, affecting mainly the superficial portion of the labia majora $[5,10]$. Although rare, vulvar tumors are the most common variety of GCT encountered in the female genital region, account for $5.3 \%$ of all GCTs [1] and in another study for 5 to 16 percent [9]. However, clitorial involvement is rare $[5,11]$. In males, the scrotum is unusual location for such tumors [6].

Clinically, the lesions mimicked a number of skin lesions, so that in one study, among 37 cases of GCT, in only 3 cases, a correct preoperative diagnosis made [3]. The main differential diagnoses of GCT in vulva, at any age, include Bartholin's duct cyst, lipoma, papilloma, hydradenoma, and fibroma. If the overlying skin is ulcerated, veneral disease or carcinoma must be excluded. Vulvar lesions in children are rare and the etiology is usually traumatic or inflammatory [4].

On histology, the tumors are non-encapsulated and composed of irregularly arranged sheets of large polyhedral cells, with a small hyperchromatic nucleus and abundant, fine to coarse, granular eosinophilic cytoplasm [5]. The intracytoplasmic granules are believed to arise from subcellular organelles as lysosomes [1]. In some cases, they are plump and irregular. The cytoplasmic granules are PAS-positive and diastase resistant. Elastosis is common in the stroma of GCT. GCT 


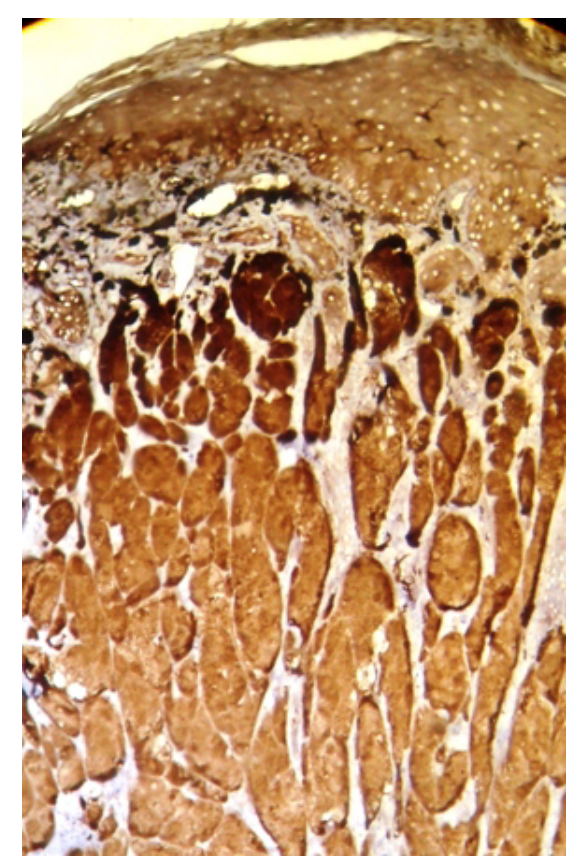

Figure 4. Positive immunohistochemical staining for S100 protein in granular cell tumor.

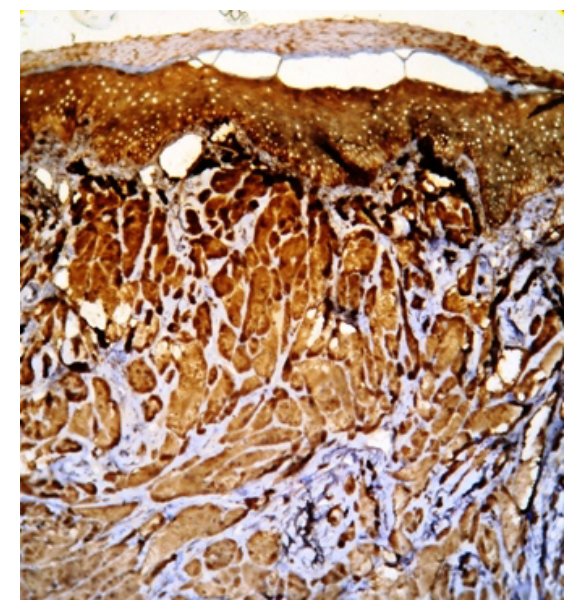

Figure 5. Positive staining for neuron specific enolase in granular cell tumor.

usually contains $\mathrm{S100}$ protein, neurone specific enolase, PGP9.5 and the melanoma- associated antigen NK1/c-3 [5]. In our case, investigations confirmed positive results for $\mathrm{S} 100$ protein and neuron specific enolase staining, but PAS staining was negative (Figures 4 and 5). This findings support the hypothesis regarding to the probable neural origin in the pathogenesis of GCT.

In one study, granular cells in scrotal GCT did not stain with smooth muscle actin antisera, suggested that this neoplasm is not of muscle origin [6]. The overlying epithelium often shows prominent psedoepitheliomatous hyperplasia [1,5], so it should be considered in the differential diagnosis of an apparently infiltrative squamous lesion of the vulva when the base of the lesion is not present in the biopsy specimen [12]. This is particularly true of tumors with a nodular, radially symmetric gross appearance. In contrast to previously published data, it was found that pseudocarcinomatous hyperplasia contained numerous mitotic figures, squamous pearls, mildly atypical nuclei, focally prominent nucleoli, and focal single cell infiltration; follicular infundibula were not preferentially involved [12].

Granular cell change has been observed in numerous neoplastic lesions, such as angiosarcomas, leiomyomas, dermatofibrosarcoma protuberans, basal cell carcinoma, ameloblastoma, oligodendroglioma, and malignant glioma $[5,10]$, must be considered in differential diagnoses of GCTs pathologically.

GCT is a locally infiltrative lesion [5]. It is benign and slowgrowing, but can cause morbidity and mortality when presenting with multicentric or multiple organ involvement due to lack of systemic therapy [13]. Although intralesional glucocorticoids have been shown to cause regression in a selected number of cases, a wide local excision is the treatment of choice, because they can, although rarely, recur after simple excision [2]. Some literatures reported that recurrences are common $[5,4,13]$. Malignant degeneration, although rare, has been reported [4].

There are no well defined criteria for malignancy. Tumor size greater than $5 \mathrm{~cm}$, vascular invasion, necrosis, and rapid growth are important indicators of malignant behaviors [5]. While rare cases of malignant GCT may retain a benign histologic appearance, previous case reports of malignancy, or aggressive behavior, in GCTs have documented six histologic criteria considered potentially important: necrosis, spindling tumor cells, vesicular nuclei with prominent nucleoli, increased mitotic rate ( $>2$ mitoses high-power field), increased N:C ratio, and pleomorphism [1]. Based on a study and literature review, a modified criterion of mitotic count $(>5 / 50 \mathrm{HPF}$ instead of $>2 / 10 \mathrm{HPF}$ ) was recommended [14].

Wide local excision with regional lymph node dissection remains the mainstay of treatment in malignant condition. Chemotherapy and radiotherapy however have not been shown to significantly improve the clinical course of the disease [14].

\section{References}

1. Althausen AM, Kowalski DP, Ludwig LE, Crry S, Greene JF (2000) Granular cell tumors: A new clinically important histologic finding. Gynecol Oncol 77: 310-313. [Crossref]

2. Hazan C, Fangman W (2007) Multiple cutaneous granular cell tumors. Dermatol Online $\mathrm{J} 13$.

3. Khansur T, Balducci L, Tavassoli M (1987) Clinical spectrum of the benign and malignant entity. Cancer 60: 220-222.

4. Cohn Z, Kapuller V, Maor E, Mares AJ (1997) Granular cell (Myoblastoma) of the Labia Major: A rare benign tumor in childhood. J Pediatr Adolesc Gynecol 12: 155156. [Crossref]

5. Laxmisha C, Thappa DM (2007) Granular cell tumor of the clitoris. J Europ Acad Dermatol Venereol 21: 392-393.

6. Craige E, Rodriguez R, Ruben B (2005) Granular cell tumor of the scrotum. Dermatol Onlin $J 11$.

7. Horowitz IR, Copas P, Majmurdar B (1995) Granular cell tumor of the vulva. Am J Obstet Gynecol 173: 1710-1714

8. Ramos PC, Kapp DS, Lonqaure TA, Tenq NN (2000) Malignant granular cell tumor of the vulva in a 17-year old: case report and literature review. Int J Gynecol Cancer 10: 429-434. [Crossref]

9. Levavi H, Sabah G, Kaplan B, Tytiun Y, Braslavsky DD, et al. (2006) Granular cell tumor of the vulva: six new cases. Arch Gynecol Obstet 273: 246-249. [Crossref]

10. Ortiz- Hidalgo, de la Vega G, Mireno-Collado C (1997) granular cell tumor (Abrikossoff tumor) of clitoris. Int J Dermatol 36: 935-937. [Crossref]

11. Degefu S, Dhurandhar HN, O’Quinn Ag, Fuller PN (1984) Granular cell tumor of the clitoris in pregnancy. Gynecol Oncol 19: 246-251. [Crossref] 
12. Wolber RA, Talerman A, Wilkinson EJ, Clement PB (1991) Vulvar granular cell tumors with psedocarcinomatous hyperplasia: a comparative analysis with differentiated squamous carcinoma. Int J Gynecol Pathol 10: 59-66. [Crossref]

13. Cheewar krianqkrai C, Sharma S, Deeb G, Lele S (2005) A rare female genital tract tumor: benign granular cell tumor of vulva: case report and review of the literature. Gynecol Oncol 97: 656-658. [Crossref]

14. Wang J, Zhu XZ, Zhang RY (2004) Malignant granular cell tumor: a clinicopathologic analysis of 10 cases with review of literature. Zhonqhua Bing Li Xue Za Zhi 33: 497502. [Crossref]

Copyright: (C2015 Yaghoobi R. This is an open-access article distributed under the terms of the Creative Commons Attribution License, which permits unrestricted use, distribution, and reproduction in any medium, provided the original author and source are credited. 